\title{
Watermelon stomach in dengue hemorrhagic fever
}

A previously healthy 69-year-old man came to our emergency room with complaints of melena, abdominal pain, poor appetite, and general myalgia. Fever had occurred four days earlier, for which a nonsteroidal anti-inflammatory drug was prescribed. Physical examination revealed normal findings. Laboratory studies showed a white blood cell count of $11.3 \times$ $10^{9} / \mathrm{L}$, hemoglobin $140 \mathrm{~g} / \mathrm{L}$, and thrombocytopenia with platelet count $15 \times 10^{9} / \mathrm{L}$. The prothrombin time and activated partial thromboplastin times were $10.8 \mathrm{sec}-$ onds (control: 11.0 seconds) and $36.6 \mathrm{sec}-$ onds (control: 29.1 seconds), respectively. Elevated liver function results (aspartate aminotransferase $271 \mathrm{U} / \mathrm{L}$, alanine aminotransferase $246 \mathrm{U} / \mathrm{L}$ ) were also noted. Urgent endoscopy revealed linear strips of erythematous mucosa radiating from the pylorus to the antrum, mimicking gastric antral vascular ectasia (also called watermelon stomach; 0 Fig.1). Active oozing was seen, and endoscopic hemostasis with argon plasma coagulation was performed successfully ( $\bullet$ Video $\mathbf{1}$ ). Tracing back his history, the patient remembered having suffered mosquito bites before the fever occurred. Serology results were positive for dengue-specific IgG and IgM. Supportive care was given and the patient's platelet count recovered to

\section{Video 1}

Endoscopic hemostasis with argon plasma coagulation in watermelon stomach in a patient with dengue hemorrhagic fever.

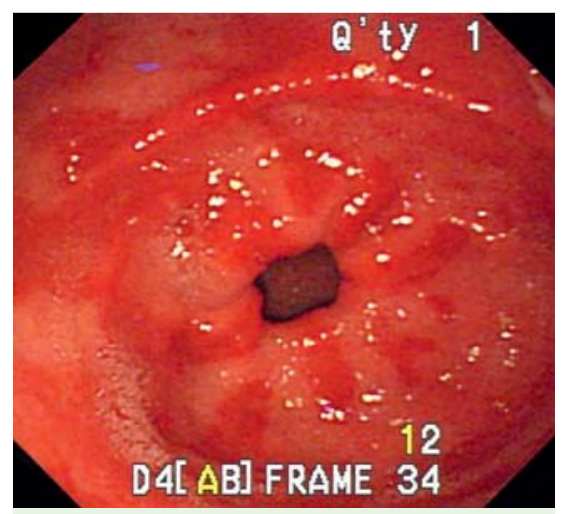

Fig. 1 Endoscopy shows linear strips of erythematous mucosa radiating from the pylorus to the antrum, mimicking gastric antral vascular ectasia (also called watermelon stomach) in a patient with dengue hemorrhagic fever.

$208 \times 10^{9} / \mathrm{L} 4$ days later. He was then discharged without recurrent bleeding episodes. However, he refused a follow-up endoscopic exam with biopsy to confirm the finding.

Typical endoscopic features of gastric antral vascular ectasia are usually seen in patients with liver cirrhosis, uremia, or autoimmune diseases, but have not been reported in dengue hemorrhagic fever. It is hypothesized that the vascular ectasia comes from intermittent obstruction of the submucosal vasculature due to partial prolapse of the loosely attached gastric mucosa of the antrum induced by vigorous peristalsis [1]. The experience from our patient is a reminder to physicians that, in addition to hemorrhagic gastritis and ulcers, watermelon stomach can appear in dengue fever.
Endoscopy_UCTN_Code_CCL_1AB_2AD_3AZ

Competing interests: None

\section{W.-H. Hsu ${ }^{1}$, I.-C. Wu ${ }^{1,2}$}

${ }^{1}$ Division of Gastroenterology, Department of Internal Medicine, Kaohsiung Medical University Hospital, Kaohsiung, Taiwan

${ }^{2}$ Department of Medicine, Faculty of Medicine, College of Medicine, Kaohsiung Medical University, Kaohsiung, Taiwan

\section{References}

1 Jabbari M, Cherry R, Lough JO et al. Gastric antral vascular ectasia: the watermelon stomach. Gastroenterology 1984; 87: $1165-1170$

\section{Bibliography}

Dol http://dx.doi.org/

10.1055/s-0032-1325887

Endoscopy 2013; 45: E35

(c) Georg Thieme Verlag KG

Stuttgart · New York

ISSN 0013-726X

Corresponding author

I.-C. Wu, MD, PhD

Division of Gastroenterology

Kaohsiung Medical University Hospital

\#100 Tz-You 1st Road

Kaohsiung City

807 Taiwan

Fax: +886-7-3135612

minica@kmu.edu.tw 